\title{
$\angle$ Research Suare \\ Stereotactic Body Radiotherapy for Metastatic and Recurrent Soft Tissue Sarcoma
}

\section{Xiaoyao Feng}

Department of Radiation Oncology,Jinling hospital,Medical school of nanjing university

Jing Li

Department of radiation oncology,Jinling hospital,Medical school of nanjing university

\section{Aomei Li}

Departmen of radiation oncology, Jinling hospital,Medical school of nanjing university

\section{Han Zhou}

Department of radiation oncology,Jinling hospital,Medical shcool of nanjing university

\section{Xixu Zhu}

Department of radiation oncology, Jinling hospital, Medical school of nanjing university

Zhen Wang ( $\nabla$ wangzhensdu@163.com )

Department of radiation oncology, Jinling hospital, Medical school of nanjing university

\section{Research}

Keywords: SBRT, STS, metastatic, recurrent

Posted Date: December 10th, 2020

DOl: https://doi.org/10.21203/rs.3.rs-122172/v1

License: (c) (i) This work is licensed under a Creative Commons Attribution 4.0 International License. Read Full License 


\section{Abstract}

Background

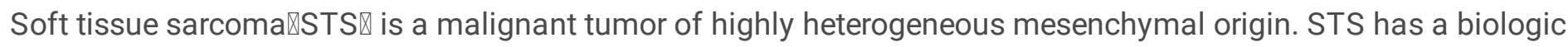
pattern and clinical transformation with localized invasive growth and susceptibility to hematogenous metastasis. Metastatic and recurrent soft tissue sarcoma may be treated by local therapeutic options, including surgery and radiation therapy. This study evaluated the safety and efficacy of SBRT for metastatic and recurrent soft tissue sarcoma.

Methods

We performed a retrospective analysis of 37 STS patients with 58 lesions treated with SBRT from 2009-2019 at our institution. We analyze the local control (LC), overall survival (OS), progression free survival (PFS) and toxicity rates of the patients.

Result

The median follow-up was 20 months $\$ range 2 to 120 months $\rrbracket$. One and two year LC rates were $75.3 \%$ and $55.2 \%$ [95\% confidence interval (Cl) 20-25 months]. Median OS was 24 months and the survival rates were $66.6 \%, 45 \%$ and $26.6 \%$ at 1, 2 and 3-year after SBRT. Median PFS were 11months (95\% Cl 8-18 months). No acute or chronic grade $\geq$ 3 toxicity was observed.

Conclusions

In patients with metastatic and recurrent STS, LC, OS and PFS were higher than expected. SBRT should be a proper treatment option for STS.

\section{Background}

Sarcomas are a rare and heterogeneous group of tumors $₫ a$ general term for a class of mesenchymal solid tumors that can occur anywhere. In 2020, it was estimated that in the USA 13130 people would be diagnosed with STS and 5350 would die of these diseases ${ }^{[2]}$. For 30 years, extended local resection and postoperative radiotherapy have remained the standard treatment for soft tissue sarcoma. An increasing number of trials on STS stereotactic body radiation therapy (SBRT) were published, with encouraging results in terms of local control (LC), toxicity and overall survival (OS) ${ }^{[3]}$.

Soft tissue sarcoma can occur anywhere in the body, most often in the extremities and trunk, and its local behavior is mainly longitudinal extension along the muscle cavity rather than direct invasion. Soft tissue sarcoma does not develop long term invasion of the lymph nodes adjacent to the draining area, a few histological subtypes may have a $15 \%$ probability of lymph node metastasis, while hematogenous dissemination is the route of widespread spread of the lesion, with the lung being the most common site of metastasis and approximately $80 \%$ of distant metastases occurring within 2-3 years of diagnosis. Treatment of recurrence and metastasis is still challenging, and radiotherapy may be an effective alternative strategy for patients in whom surgical resection is difficult or for those in whom surgery would result in serious complications. ${ }^{[5-7]}$

Stereotactic Body Radiotherapy $\varangle$ SBRT $\nabla$ refers to the type of treatment under stereotactic control, in which a high dose of radiation is given to the target area in one or less concentrated doses. It plays an important role in the treatment of 
tumors $^{[1]}$. SBRT is non-invasive and has a convenient segmentation plan that minimizes chemotherapy delays. In addition, SBRT uses rigorous fixation, advanced image guidance, and complex treatment planning and delivery systems, resulting in a highly conformal dose distribution that reduces treatment volume relative to conventional radiotherapy. This, in turn, allows each fraction to deliver large doses of radiation and increase the biologically effective dose (BED), as opposed to what traditional treatments can do ${ }^{[4]}$.

Thus, theoretically, SBRT is an attractive alternative to surgical resection, conventional radiotherapy or other palliative measures in certain patients with metastatic or recurrent soft tissue sarcoma. In the current study, we report our early institutional experience with SBRT in patients with soft tissue sarcoma.

\section{Methods And Materials}

\section{Patients}

We retrospectively searched our patient database for records of patients who received SBRT at our institution between 2009 and 2019. All patients were confirmed by biopsy pathology at the time of the first disease recurrence.

\section{SBRT}

The American Society of Therapeutic Radiology and Oncology and the American College of Radiology published guidelines for the implementation of SBRT, which is defined as "an external beam radiation therapy for the very precise delivery of high doses of radiation to extracranial targets in the body, using single doses or small fractions". [8] Indications for the treatment were discussed at the multidisciplinary tumor board. Stereotactic therapy using the CyberKnife Radiation Therapy System. The planned target volume (PTV) was obtained by isotropic expansion of 2-7 $\mathrm{mm}$ around the macroscopic lesion (bulk tumor volume, GTV) outlined on a $1.0 \mathrm{~mm}$ thick simulated CT scan. The dose was opened to the outer line of the PTV and to the 75-85\% isodose line. Different dose grading procedures were used. Efficacy was assessed using the revised solid tumor response assessment criteria (RECIST version 1.1,2009). Acute toxicity and late toxicity (within 3 months or after the end of treatment, respectively) were assessed using the Common Terminology Criteria for Adverse Events (CTCAE version 4.03,2010). Clinical assessment by physical examination and CT scan was performed at 3 and 6 months, followed by every 6 months until 5 years post-treatment or until disease progression.

\section{Definition of the endpoints}

Local failure (LF) was defined as a minimum $20 \%$ increase in the diameter of the treated volume. Local control rate (LC) was calculated for 58 lesions from the start of radiotherapy to LF or last follow-up. Overall survival (OS) was measured from the start of radiotherapy to death from any cause or the last follow-up visit.

\section{Statistical analysis}

LC PFS and OS rates for all patients were calculated from the date of the SBRT using the Kaplan-Meier method. Univariate analysis was performed using univariate analysis and a multi-logistic regression analysis to identify significant prognostic factors for LC PFS and OS. For all analyses, two-sided tests of significance were used with P values $<0.05$ considered significant. All statistical analyses were performed using the Statistical Package for the Social Sciences (version 22.0; SPSS).

\section{Results}


Patient- and treatment-related characteristics

Between June 2009 and June 2019ه37 patients with 58 lesions were treated in this study. As the table 1 shows, the mean age was 55 years (range, 19-82 years). The number of lesions at the first SBRT less than 3 and equal or more than 3 was $27(73 \%)$ and $10(27 \%)$. Together, the number of high differentiation $\otimes$ moderately differentiation and poor differentiation was $19(51 \%), 4(11 \%)$ and $14(38 \%)$.

Table 1 Patient-related characteristics in STS patients treated by SBRT (per patient)

\begin{tabular}{|c|c|c|}
\hline Patient-related variables $(n=37)$ & Patients, $\mathrm{n}$ & $\%$ \\
\hline \multicolumn{3}{|l|}{ Age } \\
\hline$<60$ & 18 & 49 \\
\hline$\geq 60$ & 19 & 51 \\
\hline \multicolumn{3}{|l|}{ Gender } \\
\hline Male & 25 & 68 \\
\hline Female & 12 & 32 \\
\hline \multicolumn{3}{|l|}{ Pathological type } \\
\hline leimyosarcoma & 3 & 8 \\
\hline Spindle cell tumor & 6 & 16 \\
\hline Malignant fibroblastoma & 8 & 22 \\
\hline fibrosarcoma & 3 & 8 \\
\hline liposarcoma & 4 & 11 \\
\hline Others & 13 & 35 \\
\hline \multicolumn{3}{|l|}{ Grading } \\
\hline high differentiation & 19 & 51 \\
\hline Intermediate differentiation & 4 & 11 \\
\hline low differentiation & 14 & 38 \\
\hline \multicolumn{3}{|c|}{ Number of concurrent metastases at the time of first SBRT } \\
\hline$<3$ & 27 & 73 \\
\hline$\geq 3$ & 10 & 27 \\
\hline
\end{tabular}

Table 2 Treatment-related characteristics in metastases or local recurrences treated by SBRT (per treatment) 


\begin{tabular}{|lll|}
\hline Treatment-related variables $(n=58)$ & Treatments, $n$ & $\%$ \\
\hline Site & 6 & 10 \\
\hline Head and neck & 17 & 30 \\
\hline Chest & 5 & 9 \\
\hline Abdominal pelvic & 13 & 22 \\
\hline renal region & 5 & 9 \\
\hline Vertebral body bone & 10 & 17 \\
\hline limbs & 2 & 3 \\
\hline Diameter & & \\
\hline$<50 m m$ & 26 & 45 \\
\hline $\mathbf{5 0}$ mm & 32 & 55 \\
\hline BED & & \\
\hline$<100 G y$ & 29 & 50 \\
\hline$\geq 100 G y$ & 29 & 50 \\
\hline
\end{tabular}

Abbreviations $\triangle B E D \otimes$ biologically equivalent dose $B E D$ values calculate using $\mathrm{a} / \beta=10$.

Table 3 The dosimetry index of the patients during Cyber-knife radiosurgery treatmet

\begin{tabular}{|c|c|c|c|c|c|c|c|c|}
\hline Item & $\mathrm{Cl}$ & $\mathrm{nCl}$ & $\mathrm{HI}$ & $\begin{array}{l}\text { Coverage } \\
\bigotimes \% \bigotimes\end{array}$ & PTV『cm3】 & $\begin{array}{l}\text { Prescription dose } \\
\text { 『Gy }\end{array}$ & $\mathrm{fx}$ & $\begin{array}{l}\text { Isodose } \\
\square \% \square\end{array}$ \\
\hline Range & $\begin{array}{l}1.00- \\
2.77\end{array}$ & $\begin{array}{l}1.13- \\
2.93\end{array}$ & $\begin{array}{l}1.10- \\
2.00\end{array}$ & $\begin{array}{l}47.81- \\
99.75\end{array}$ & $\begin{array}{l}2.02- \\
1878.09\end{array}$ & $20-75$ & $1-10$ & $50-88$ \\
\hline Mean & 1.31 & 1.61 & 1.39 & 82.52 & 307.03 & 44.81 & 4.33 & 73.26 \\
\hline Median & 1.13 & 1.42 & 1.33 & 86.12 & 83.25 & 45 & 5 & 75 \\
\hline
\end{tabular}

Abbreviations: Coverage: the coverage is volume of the tumor receiving greater than or equal to the prescription dose divided by the total volume of the tumor times $100 ; \mathrm{Cl}$, conformity index; $\mathrm{nCl}$, new conformity index; $\mathrm{HI}$, homogeneity index.

\section{Local control}

Among the 58 lesions in the 37 patients in this study, the median local control time was 25 months and $95 \% \mathrm{Cl}$ was 20-25 months. A Kaplan-Meier plot for overall survival is shown in Fig. 2A.One year local control rate was $75.3 \%$ and 
$55.2 \%$ in 2 years. Among them, LC with low differentiation sarcoma was better than high differentiation $(P=0.0201)$, LC with tumor diameter less than or equal $5 \mathrm{~cm}$ was better $(P=0.0081)$, and was independent of $B E D(P=0.0891)$.

\section{Overall survival}

In this study, the median time of OS was 24 months, and $95 \% \mathrm{Cl}$ was $12.0-35.0$ months. A Kaplan-Meier plot for overall survival is shown in Fig. 2A. 1-year OS was 66.6\%, 2-years OS was 45\%, and 3-years OS was $26.2 \%$. Among them, OS was related to systemic status, and single lesion was better, $P=0.0069$. Median OS of single lesion was 28 months, $95 \% \mathrm{Cl}$ was $21-75,1$-year and 3 -year survival rates were $100 \%$ and $50.5 \%$, respectively. The median OS of multiple lesions was 11 months, $95 \% \mathrm{Cl}$ was $4.00-26.00$, and the 1 -year and 3 -years survival rates were $45.3 \%$ and $11.3 \%$ respectively.

\section{Progression-free survival}

A Kaplan-Meier plot for progression-free survival is shown in Fig. 3. 1-year PFS is $44.9 \%$ and 2-years PFS is 26.2\%.The median PFS of single lesion was 15 months, $95 \% \mathrm{Cl} 8.00-31.00$, and the 1-year and 2-years progressionfree survival rates were $53.2 \%$ and $37.3 \%$, respectively. The median PFS of multiple lesions was August, $95 \% \mathrm{Cl} 3.00$ 13.00, and the 1-year and 2-year progression-free survival rates were $26.6 \%$ and $0 \%$, respectively. In addition, lowgrade lesion PFS was superior to high-grade lesion PFS, p=0.0006, low-grade median PFS was 25 months, $95 \% \mathrm{Cl}$ was 11.00-77.00, 1-year and 2-year progression-free survival rates were 76.9\% and 57.7\%, 1-year and 2-year progression-free survival rates were 8 months $₫ 95 \% \mathrm{Cl} 4-10 \rrbracket, 1$-year and 2-year progression-free survival rates were $22.4 \%$ and $5.5 \%$, respectively.

\section{Univariate Analysis and A Multi-Logistic Regression Analysis}

Univariate and multivariate regression analysis were used to determine which factors were associated with LC, OS and PFS. Multivariate analysis for LC was associated with pathological grade, tumor size, and number of tumors at the time of first SBRT treatment, but not with BED. In univariate analysis, it was only related to pathological grade and tumor size, but not to BED and the number of tumors at the time of first SBRT treatment. Univariate and multivariate analysis of OS and PFS were related to pathological grade and the number of tumors at the time of first SBRT treatment, but not to BED and tumor size.

Table 4 Univariate analysis of PFS and OS 


\begin{tabular}{|c|c|c|c|c|}
\hline \multirow[t]{2}{*}{ Variable } & OS & $p$ & PFS & $p$ \\
\hline & \multicolumn{2}{|l|}{$\mathrm{HR}$ and $95 \% \mathrm{Cl}$} & \multicolumn{2}{|l|}{$\mathrm{HR}$ and $95 \% \mathrm{Cl}$} \\
\hline \multicolumn{5}{|l|}{ Grading } \\
\hline poor differentiation & $\begin{array}{l}0.205 \rrbracket 0.075- \\
0.564 \rrbracket\end{array}$ & 0.002 & $\begin{array}{l}0.234 \llbracket 0.095- \\
0.580 \rrbracket\end{array}$ & 0.002 \\
\hline High or moderately differentiation & 1 & & 1 & \\
\hline \multicolumn{5}{|l|}{ Diameter } \\
\hline$\leq 50 \mathrm{~mm}$ & $\begin{array}{l}0.873 \llbracket 0.386- \\
1.971 \rrbracket\end{array}$ & 0.743 & $\begin{array}{l}0.822 \varangle 0.362- \\
1.863 \rrbracket\end{array}$ & 0.638 \\
\hline$>50 \mathrm{~mm}$ & 1 & & 1 & \\
\hline \multicolumn{5}{|l|}{ BED } \\
\hline$\geq 100$ Gy & $\begin{array}{l}0.628 \llbracket 0.284- \\
1.392 \rrbracket\end{array}$ & 0.252 & $\begin{array}{l}0.597 \rrbracket 0.269- \\
1.327 \rrbracket\end{array}$ & 0.206 \\
\hline$<100 G y$ & 1 & & 1 & \\
\hline \multicolumn{5}{|c|}{$\begin{array}{l}\text { Number of concurrent metastases at the time of first } \\
\text { SBRT }\end{array}$} \\
\hline$<3$ & $\begin{array}{l}0.349 \llbracket 0.151- \\
0.804 \rrbracket\end{array}$ & 0.013 & $\begin{array}{l}0.372 \rrbracket 0.155- \\
0.892 \rrbracket\end{array}$ & 0.027 \\
\hline$\geq 3$ & 1 & & 1 & \\
\hline
\end{tabular}

Table 5 A Multi-Logistic Regression Analysis of PFS and OS

\begin{tabular}{|lll|}
\hline \multirow{2}{*}{ Grading } & $\mathrm{PFS}$ & $\mathrm{OS}$ \\
\cline { 2 - 3 } Number of concurrent metastases at the time of first SBRT & $\mathrm{P}=0.002$ & $\mathrm{P}=0.002$ \\
\cline { 2 - 3 } & $\mathrm{HR} 0.231(0.092-0.579)$ & $\mathrm{HR} 0.174(0.059-0.512)$ \\
\cline { 2 - 3 } & $\mathrm{HR} 0.303(0.112-0.819)$ & $\mathrm{P}=0.008$ \\
\hline
\end{tabular}

Table 6 Univariate Analysis and A Multi-Logistic Regression Analysis of LC 


\begin{tabular}{|c|c|c|c|c|}
\hline \multicolumn{5}{|l|}{ Local Control } \\
\hline & \multirow{2}{*}{$\begin{array}{l}\text { A Multi- } \\
\text { Logistic Regression Analysis }\end{array}$} & \multicolumn{3}{|l|}{ Univariate Analysis } \\
\hline & & & $\begin{array}{l}\mathrm{HR} \text { and } \\
95 \% \mathrm{Cl}\end{array}$ & $\mathrm{p}$ \\
\hline \multirow[t]{3}{*}{ Grading } & $P=0.018$ & \multirow{2}{*}{$\begin{array}{l}\text { poor } \\
\text { differentiation }\end{array}$} & \multirow{2}{*}{$\begin{array}{l}0.282 \\
\varangle 0.091- \\
0.879 \square\end{array}$} & \multirow[t]{2}{*}{0.029} \\
\hline & \multirow[t]{2}{*}{ HR $\otimes 0.225 \otimes 0.066-0.770 \rrbracket$} & & & \\
\hline & & $\begin{array}{l}\text { High or } \\
\text { moderately } \\
\text { differentiation }\end{array}$ & 1 & \\
\hline \multirow[t]{3}{*}{ Diameter } & \multirow{3}{*}{$\begin{array}{l}P=0.040 \\
H R \otimes 0.224 \llbracket 0.054-0.932 \rrbracket\end{array}$} & $\leq 50 \mathrm{~mm}$ & \multirow{2}{*}{$\begin{array}{l}0.170 \\
\rrbracket 0.038- \\
0.761 \rrbracket\end{array}$} & \multirow[t]{2}{*}{0.021} \\
\hline & & & & \\
\hline & & $>50 \mathrm{~mm}$ & 1 & \\
\hline \multirow[t]{2}{*}{ BED } & $P=0.056$ & $\geq 100 \mathrm{~Gy}$ & 1 & \multirow[t]{2}{*}{0.107} \\
\hline & $H R \bowtie 3.839 ه 0.965-15.269 \rrbracket$ & $<100 G y$ & $\begin{array}{l}2.880 \\
\llbracket 0.797- \\
10.409 \rrbracket\end{array}$ & \\
\hline \multirow{3}{*}{$\begin{array}{l}\text { Number of concurrent metastases } \\
\text { at the time of first SBRT }\end{array}$} & $P=0.013$ & \multirow[t]{2}{*}{$<3$} & \multirow{2}{*}{$\begin{array}{l}0.538 \\
\otimes 0.166- \\
1.740 \rrbracket\end{array}$} & \multirow[t]{2}{*}{0.301} \\
\hline & \multirow[t]{2}{*}{ HR囚0.155ه0.036-0.671ه } & & & \\
\hline & & $\geq 3$ & 1 & \\
\hline
\end{tabular}

\section{Case presentation}

The patient is a 71-year-old male with a mucinous liposarcoma of the medial thigh. The first surgical resection was performed on 2000-08-29, followed by in situ recurrence followed by tumor resection on 2008-12-10, 2011-02-14, 2016-06-20, 2017-08-13, and 2018-11-19, respectively. The postoperative pathology was all mucinous liposarcoma. In May 2019, the patient's repeat MRI suggested a recurrence of Stereotactic radiotherapy for recurrent lesions was performed on 2019-06-06 with a specific plan of 50Gy/5fx. As shown in Figure 4, review after 1 year of treatment suggests disease reduction.

\section{Toxicity}

There have been no cases of acute or late grade 4 toxicity or possible treatment-related death. The most common acute toxicity was grades $1-2$ fatigue ( $8 / 37,21.6 \%)$. Acute grades $1-2$ radiation pneumonitis occurred in one patients $(2.7 \%)$, and acute grade $1-2$ radiation enteritis was observed in two patients $(2.7 \%)$. Late grade 3 radiation dermatitis was observed in one patient $(2.7 \%)$ at 6 months after SBRT.

\section{Discussion}

Sarcomas are heterogenous malignancies of mesenchymal origin and are classified into more than 100 distinct subtypes. Due to the biology of the tumor, soft tissue sarcoma is prone to recurrence and metastasis. According to the guideline recommendations, the treatment of choice for this tumor is surgery, and in some patients, after multiple surgeries, it is difficult to undergo surgery again, in which case radiotherapy can be an alternative local treatment. 
Soft tissue sarcomas are prone to recurrence and metastasis. Recurrent and metastatic soft tissue sarcomas are often difficult to treat surgically due to anatomical location limitations, At the same time, drug therapy for soft tissue sarcomas that cannot be surgically resected has limited efficacy, and stereotactic radiotherapy targeting primary and metastatic lesions of soft tissue sarcomas is available.

In recent years, SBRT has been increasingly used for patients with tumors that are not candidates for surgery. In lung cancer, for example, it is now the standard treatment option for early-stage inoperable non-small cell lung cancer due to its superior efficacy. ${ }^{[9]}$ Likewise, SBRT plays an important role in hepatopulmonary metastases from colon and breast cancers ${ }^{[10-11]}$. For patients with recurrence and metastasis, several small, single-institution retrospective studies have shown that SBRT has a relatively high local control rate and low toxicity in the treatment of sarcoma $\mathrm{PM}^{[19-21]}$. Numerous retrospective studies have shown that SBRT can provide durable local control of lung metastases from soft tissue sarcomas. In response to SBRT versus surgery, C. Tetta et al study showed that topically applied SBRT for STS lung metastases was associated with lower cumulative overall mortality and similar overall and disease-free survival compared to surgery ${ }^{[22]}$. In contrast, SBRT was associated with higher disease survival

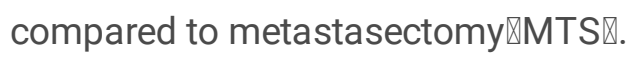

Current studies on the role of SBRT in soft tissue sarcoma including primary and metastatic lesions are shown in the table $7^{[12-13]}$. Based on their experience. Previous studies addressing the role of SBRT in sarcoma have focused on metastases of the lung and spine, with Billingsley et al ${ }^{[14]}$. reporting a median OS of 33 months after resection of lung metastases compared to 11 months for nonsurgical treatment. However, most SBRT studies reported median overall survival of less than 30 months. ${ }^{[15-19]}$ In our study, the OS was 24 months, probably due to the fact that the selected patients were recurrent and metastatic patients who had received multiple treatments and almost all of them had more than one metastatic lesion before undergoing SBRT. In the study, $70 \%$ received surgery prior to stereotactic radiotherapy, $49 \%$ received chemotherapy, and $32 \%$ received both surgery and chemotherapy.

Table 7. Summary of studies on stereotactic body radiotherapy for sarcoma

\begin{tabular}{|c|c|c|c|c|c|c|c|c|}
\hline Study & Site & $\begin{array}{l}\mathrm{N} \\
\text { Patients }\end{array}$ & $\begin{array}{l}\mathrm{N} \\
\text { Metastases }\end{array}$ & $\begin{array}{l}\text { Dose } \\
\text { and } \\
\text { fraction } \\
\text { of } \\
\text { radiation }\end{array}$ & LC & OS & DMFS & $\begin{array}{l}\text { Median } \\
\text { Follow- } \\
\text { up }\end{array}$ \\
\hline $\begin{array}{l}\text { Mauro Loi } \\
2018\end{array}$ & Mixed & 16 & 26 & $\begin{array}{l}30- \\
60 \mathrm{~Gy} / 1- \\
6 \mathrm{fx}\end{array}$ & 4years $₫ 78 \%$ & $\begin{array}{l}\text { Median『 } \\
69 \text { months }\end{array}$ & 17 months & 36 \\
\hline $\begin{array}{l}\text { Christina } \\
\text { Linder } \\
\text { Stragliotto } \\
2012\end{array}$ & Mixed & 46 & 136 & $\begin{array}{l}10- \\
48 \mathrm{~Gy} / 1- \\
5 f x\end{array}$ & - & $\begin{array}{l}\text { Median } \mathbb{} \\
26 \text { months }\end{array}$ & - & 22 \\
\hline Our study & Mixed & 37 & 58 & $\begin{array}{l}20- \\
75 \mathrm{~Gy} / 1- \\
10 \mathrm{fx}\end{array}$ & $\begin{array}{l}\text { One } \\
\text { year:75.3\% } \\
\text { Two } \\
\text { years:55.2\% }\end{array}$ & $\begin{array}{l}\text { Median } \rrbracket \\
\text { 24months }\end{array}$ & - & 20 \\
\hline
\end{tabular}

Based on common sense speculation, the relevant factors affecting the efficacy of SBRT may be tumor size, prescribed dose, and histology. The prognosis of soft tissue sarcoma is inferred by the interaction of multiple factors, including varying characteristics of the patient, varying characteristics of tumorigenesis and presentation and 
specificity of the different modalities, sequences and combinations of combination therapy, so that even the conclusions obtained from a single-factor analysis or even a multifactor analysis, evaluated in a number of reports, reveal the impact of the bias of the selection criteria of the patient and the limitation of the sample size. In our study, patients' OS and PFS were not related to biologically equivalent dose (BED), but to tumor grade and number of tumors at the time of first treatment. In the regression analysis for LC, multivariate analysis was related to pathological grade, tumor size and number of tumors at first SBRT treatment, but not to BED. In the univariate analysis, it was only related to pathologic grade and tumor size. We can infer that the prognosis of soft tissue sarcoma is related to the characteristics of the tumor itself rather than the characteristics of the treatment.

The treatment response in this study was mild, mainly grade 1-2 fatigue and radiation pneumonia, with only one case of grade 3 skin reaction, the side effects of this treatment were mild, may be related to the relatively low impact of SBRT on normal tissues. The local response was comparable to surgical intervention, and the long-term survival rate ([36 months]) of 30\% for metastatic sarcoma was significant, compared to an overall 5-year survival rate of approximately $70 \%$ for non-metastatic sarcoma ${ }^{[23]}$. This demonstrates the effectiveness of SBRT in metastatic sarcoma and the urgent need for further development and evaluation of this approach in future controlled clinical trials.

There are several limitations of our study. First, the number of cases in this study is small. And as a retrospective study of patients treated over a long period of time, selection bias cannot be excluded. Due to the rarity of the disease, a multicenter, clinically controlled study is necessary.

\section{Conclusion}

Stereotactic radiation therapy might offer a useful alter-native to surgery in the treatment of metastatic and recurrent Such therapy is well tolerated and provides a realistic opportunity for eradication, or at least stabilization, of metastatic lesions.

\section{Abbreviations}

STSUSoft tissue sarcoma

SBRTDStereotactic Body Radiotherapy

LCLLocal control

OSロOverall survival

PFSIProgression free survival

ClaConfidence interval

BEDaBiologically effective dose

PTV: Planned target volume

GTV: Gross tumor volume

LF: Local failure

Page $10 / 20$ 
BED: Biologically equivalent dose

Cl: Conformity index

$\mathrm{nCl}$ : New conformity index

Hl: Homogeneity index

MTS: Metastasectomy

\section{Declarations}

\section{Ethics approval and consent to participate}

The study protocol was in accordance with the ethical guidelines of the Declaration of Helsinki and was approved by the independent ethics committees at Jinling Hospital. In addition, all inclusion patients gave written informed consent.

\section{Consent for publication:}

Not applicable.

\section{Availability of data and materials:}

The datasets supporting the conclusions of this article are included within the article and its additional files. They are also available from the corresponding author on reasonable request.

\section{Competing interests:}

The authors declare that they have no competing interests.

\section{Funding:}

This work was supported by the Science and Technology Plan of Jiangsu Province, Social Development-General Project of China (No BE2015688).

\section{Authors' contributions:}

Xiaoyao Feng: Methodology $₫$ Software $\bigotimes$ Writing- Original draft preparation. Jing Li: Conceptualization $\llbracket$ Methodology $\bigotimes$ Software. Zhen Wang: Visualization, Investigation, Writing - Review \& Editing®Formal analysis. Aomei Li: Project administration. Han Zhou: Data curation, Investigation, Writing - Review \&Editing. Xi-xu Zhu『Funding acquisition $\bigotimes$ Supervision $₫$ Validation.

\section{Acknowledgements:}

We want to thank reviewers for their valuable comments, also want to thank to Dr. xixu-zhu for his valuable comments.

\section{References}


1. Macdermed DM, Weichselbaum RR, Salama JK. A rationale for the targeted treatment of oligometastases with radiotherapy. J Surg Oncol. 2008;98(3):202-206. doi:10.1002/jso.21102

2. Siegel RL, Miller KD, Jemal A. Cancer statistics, 2020. CA Cancer J Clin. 2020;70(1):7-30. doi:10.3322/caac. 21590

3. Blumenfeld P, Sen N, Abrams R, Wang D. Advances in Radiation Therapy for Primary and Metastatic Adult Soft Tissue Sarcomas. Curr Oncol Rep. 2016;18(6):36. doi:10.1007/s11912-016-0523-z

4. Qiu B, Aili A, Xue L, Jiang P, Wang J. Advances in Radiobiology of Stereotactic Ablative Radiotherapy. Front Oncol. 2020;10:1165. Published 2020 Aug 7. doi:10.3389/fonc.2020.01165

5. van Geel AN, Hoekstra HJ, van Coevorden F, Meyer S, Bruggink ED, Blankensteijn JD. Repeated resection of recurrent pulmonary metastatic soft tissue sarcoma. Eur J Surg Oncol. 1994;20(4):436-440.

6. Blackmon SH, Shah N, Roth JA, et al. Resection of pulmonary and extrapulmonary sarcomatous metastases is associated with long-term survival. Ann Thorac Surg. 2009;88(3):877-885. doi:10.1016/j.athoracsur.2009.04.144

7. Hoefkens F, Dehandschutter C, Somville J, Meijnders P, Van Gestel D. Soft tissue sarcoma of the extremities: pending questions on surgery and radiotherapy. Radiat Oncol. 2016;11(1):136. Published 2016 Oct 12. doi:10.1186/s13014-016-0668-9

8. Potters L, Kavanagh B, Galvin JM, et al. American Society for Therapeutic Radiology and Oncology (ASTRO) and American College of Radiology (ACR) practice guideline for the performance of stereotactic body radiation therapy. Int J Radiat Oncol Biol Phys. 2010;76(2):326-332. doi:10.1016/j.ijrobp.2009.09.042

9. Shinde A, Li R, Kim J, Salgia R, Hurria A, Amini A. Stereotactic body radiation therapy (SBRT) for early-stage lung cancer in the elderly. Semin Oncol. 2018;45(4):210-219. doi:10.1053/j.seminoncol.2018.06.002

10. Kobiela J, Spychalski P, Marvaso G, et al. Ablative stereotactic radiotherapy for oligometastatic colorectal cancer: Systematic review. Crit Rev Oncol Hematol. 2018;129:91-101. doi:10.1016/j.critrevonc.2018.06.005

11. Shibamoto Y, Murai T, Suzuki K, et al. Definitive Radiotherapy With SBRT or IMRT Boost for Breast Cancer: Excellent Local Control and Cosmetic Outcome. Technol Cancer Res Treat. 2018;17:1533033818799355. doi:10.1177/1533033818799355

12. Loi M, Duijm M, Baker S, et al. Stereotactic body radiotherapy for oligometastatic soft tissue sarcoma. Radiol Med. 2018;123(11):871-878. doi:10.1007/s11547-018-0912-5

13. Stragliotto CL, Karlsson K, Lax I, et al. A retrospective study of SBRT of metastases in patients with primary sarcoma. Med Oncol. 2012;29(5):3431-3439. doi:10.1007/s12032-012-0256-2

14. Billingsley KG, Burt ME, Jara E, et al. Pulmonary metastases from soft tissue sarcoma: analysis of patterns of diseases and postmetastasis survival. Ann Surg. 1999;229(5):602-612. doi:10.1097/00000658-19990500000002

15. Dhakal S, Corbin KS, Milano MT, et al. Stereotactic body radiotherapy for pulmonary metastases from soft-tissue sarcomas: excellent local lesion control and improved patient survival. Int J Radiat Oncol Biol Phys. 2012;82(2):940-945. doi:10.1016/j.ijrobp.2010.11.052

16. Stragliotto CL, Karlsson K, Lax I, et al. A retrospective study of SBRT of metastases in patients with primary sarcoma. Med Oncol. 2012;29(5):3431-3439. doi:10.1007/s12032-012-0256-2

17. Chang UK, Cho WI, Lee $\mathrm{DH}$, et al. Stereotactic radiosurgery for primary and metastatic sarcomas involving the spine. J Neurooncol. 2012;107(3):551-557. doi:10.1007/s11060-011-0777-0

18. Folkert MR, Bilsky MH, Tom AK, et al. Outcomes and toxicity for hypofractionated and single-fraction imageguided stereotactic radiosurgery for sarcomas metastasizing to the spine. Int J Radiat Oncol Biol Phys. 2014;88(5):1085-1091. doi:10.1016/j.ijrobp.2013.12.042

Page $12 / 20$ 
19. Baumann BC, Nagda SN, Kolker JD, et al. Efficacy and safety of stereotactic body radiation therapy for the treatment of pulmonary metastases from sarcoma: A potential alternative to resection. J Surg Oncol. 2016;114(1):65-69. doi:10.1002/jso.24268

20. Soyfer V, Corn BW, Shtraus N, et al. Single-institution Experience of SBRT for Lung Metastases in Sarcoma Patients. Am J Clin Oncol. 2017;40(1):83-85. doi:10.1097/COC.0000000000000103

21. Lindsay AD, Haupt EE, Chan CM, et al. Treatment of Sarcoma Lung Metastases with Stereotactic Body Radiotherapy. Sarcoma. 2018;2018:9132359. Published 2018 Apr 1. doi:10.1155/2018/9132359

22. Tetta C, Londero F, Micali LR, et al. Stereotactic Body Radiotherapy Versus Metastasectomy in Patients With Pulmonary Metastases From Soft Tissue Sarcoma. Clin Oncol (R Coll Radiol). 2020;32(5):303-315. doi:10.1016/j.clon.2020.01.005

23. Mendenhall WM, Indelicato DJ, Scarborough MT, et al. The management of adult soft tissue sarcomas. Am J Clin Oncol. 2009;32(4):436-442. doi:10.1097/COC.0b013e318173a54f

\section{Figures}

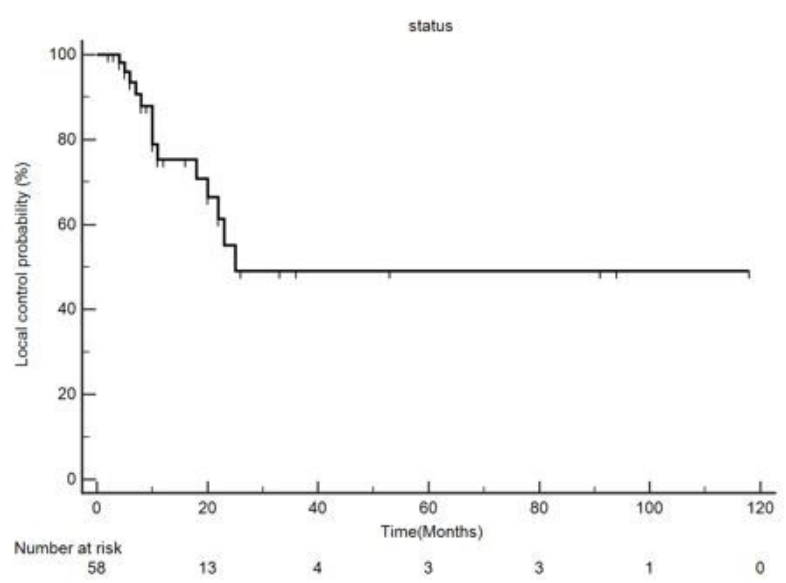

a

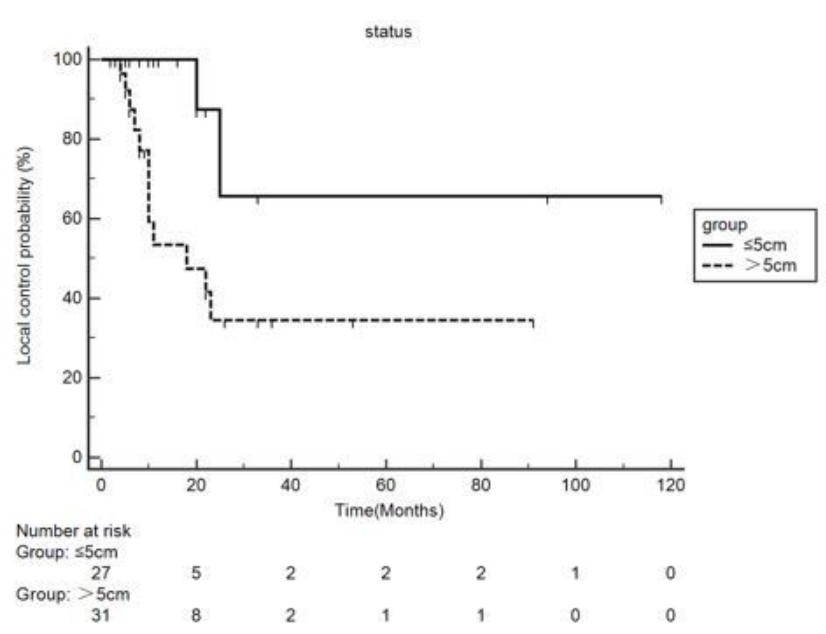

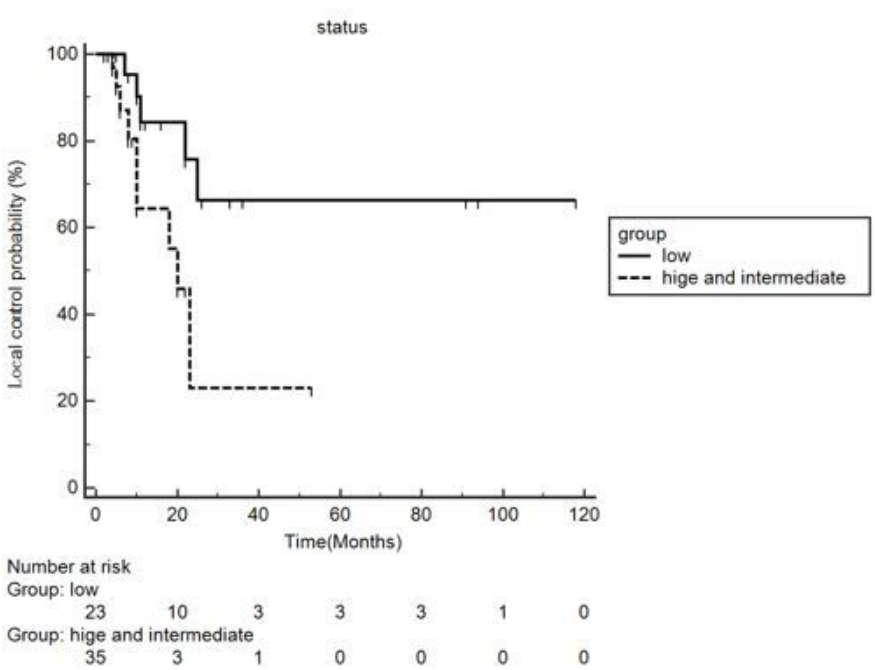

b

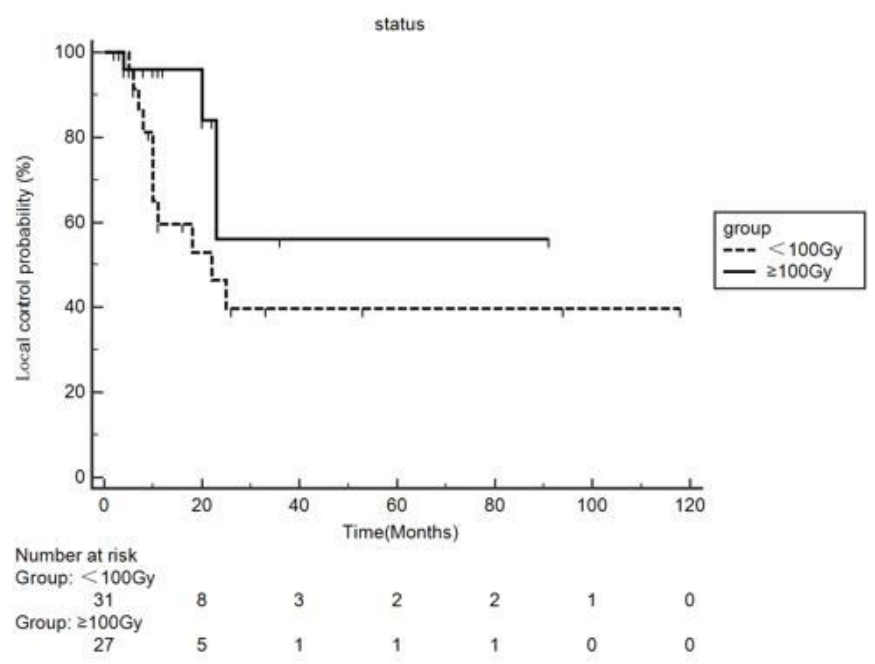


Figure 1

Kaplan-Meier plots for: a local control following stereotactic body radiation therapy (SBRT). b Local con-trol following SBRT stratified by low differentiation (dashed line) and high and intermediate (solid line).c Local con-trol following SBRT stratified by tumor diameter less than or equal $5 \mathrm{~cm}$ (dashed line) and more than $5 \mathrm{~cm}$ (solid line). d Local con-trol following SBRT stratified by BED<100Gy (dashed line) and BED $\geq 100 \mathrm{~Gy}$ (solid line).
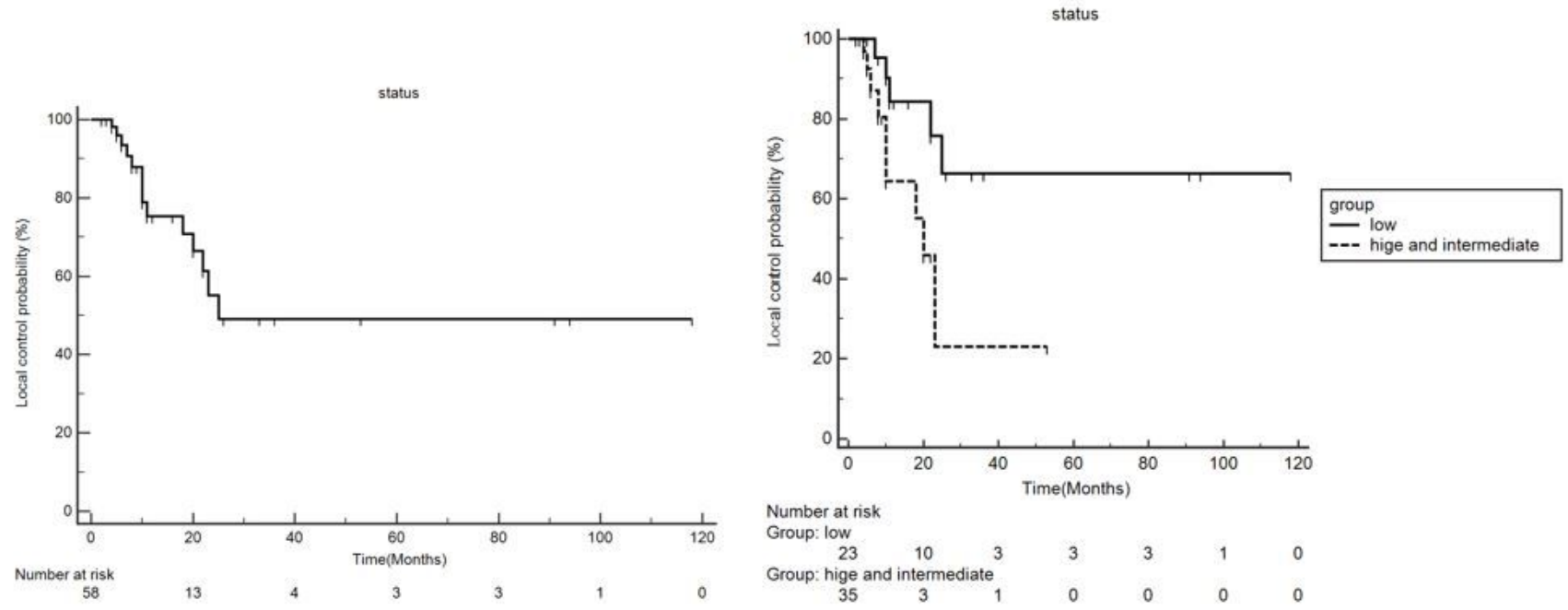

a

b
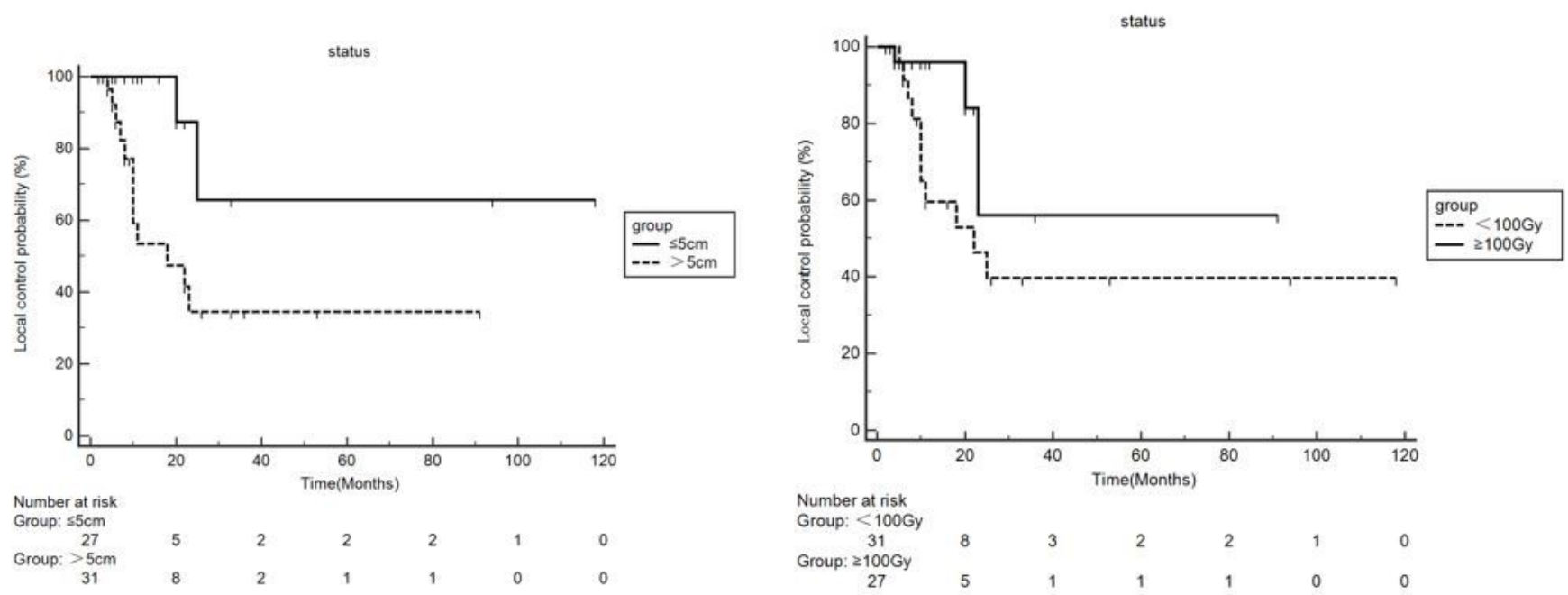

c

d

\section{Figure 1}

Kaplan-Meier plots for: a local control following stereotactic body radiation therapy (SBRT). b Local con-trol following SBRT stratified by low differentiation (dashed line) and high and intermediate (solid line).c Local con-trol following SBRT stratified by tumor diameter less than or equal $5 \mathrm{~cm}$ (dashed line) and more than $5 \mathrm{~cm}$ (solid line). $d$ Local con-trol following SBRT stratified by BED<100Gy (dashed line) and BED $\geq 100 \mathrm{~Gy}$ (solid line). 

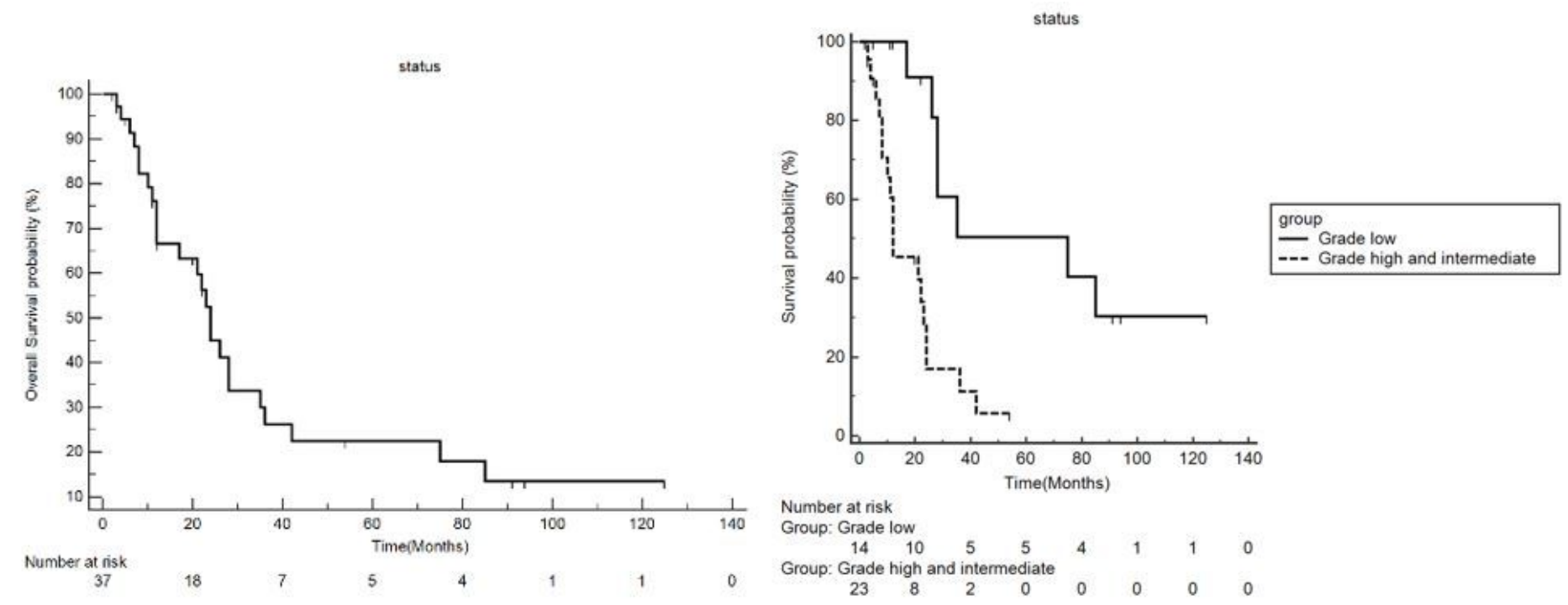

a

b

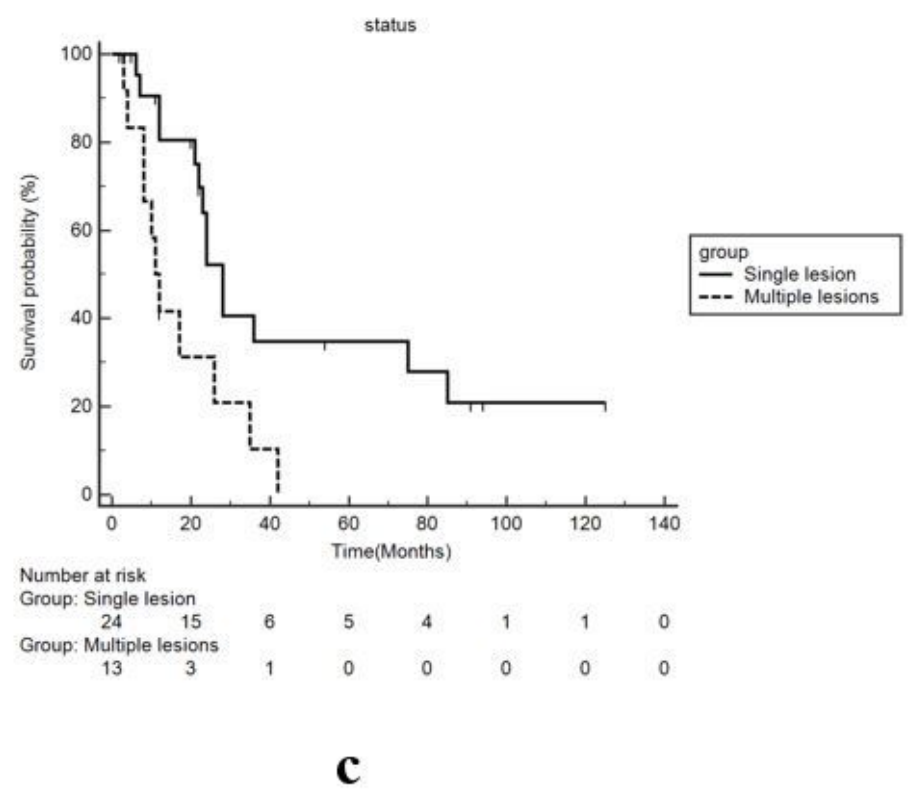

Figure 2

Kaplan-Meier plots for: a overall survival following stereotactic body radiation therapy (SBRT). b Overall survival following SBRT stratified by low differentiation (dashed line) and high and intermediate (solid line). c Overall survival following SBRT stratified by single lesion (dashed line) and multiple alesions (solid line) 

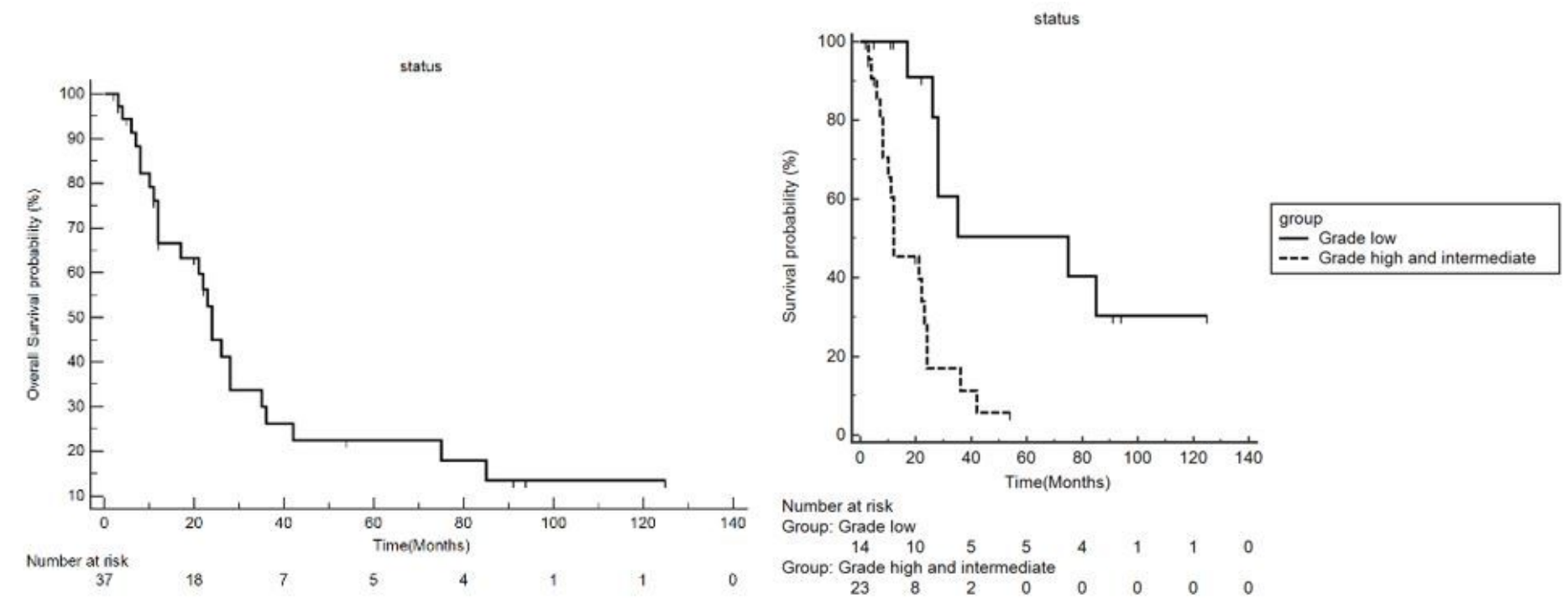

a

b

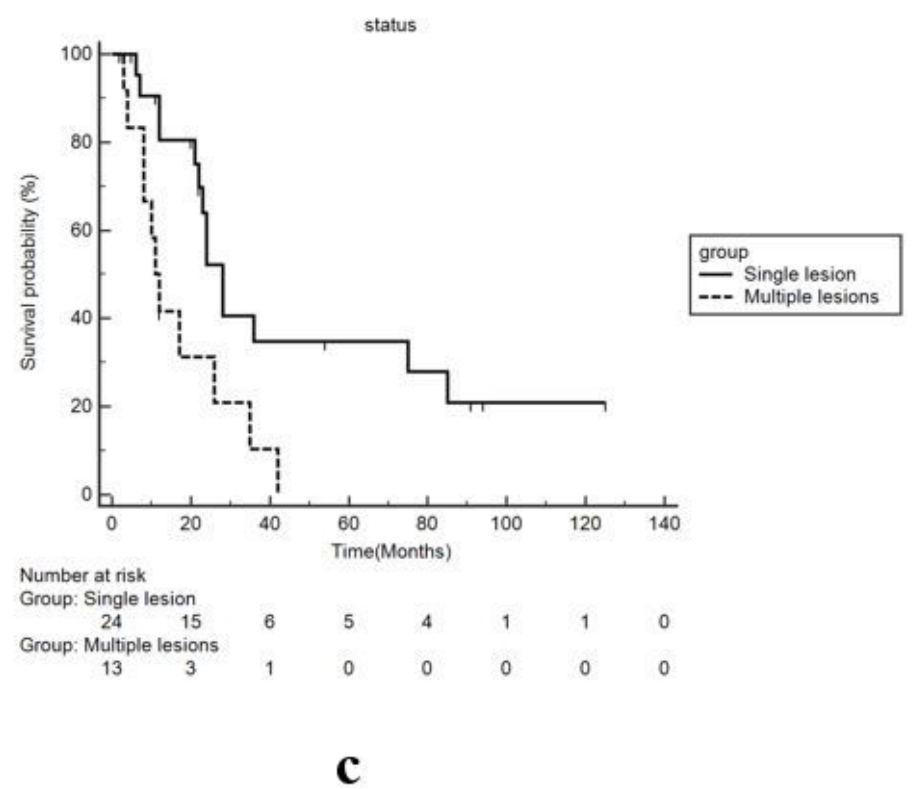

Figure 2

Kaplan-Meier plots for: a overall survival following stereotactic body radiation therapy (SBRT). b Overall survival following SBRT stratified by low differentiation (dashed line) and high and intermediate (solid line). c Overall survival following SBRT stratified by single lesion (dashed line) and multiple alesions (solid line) 

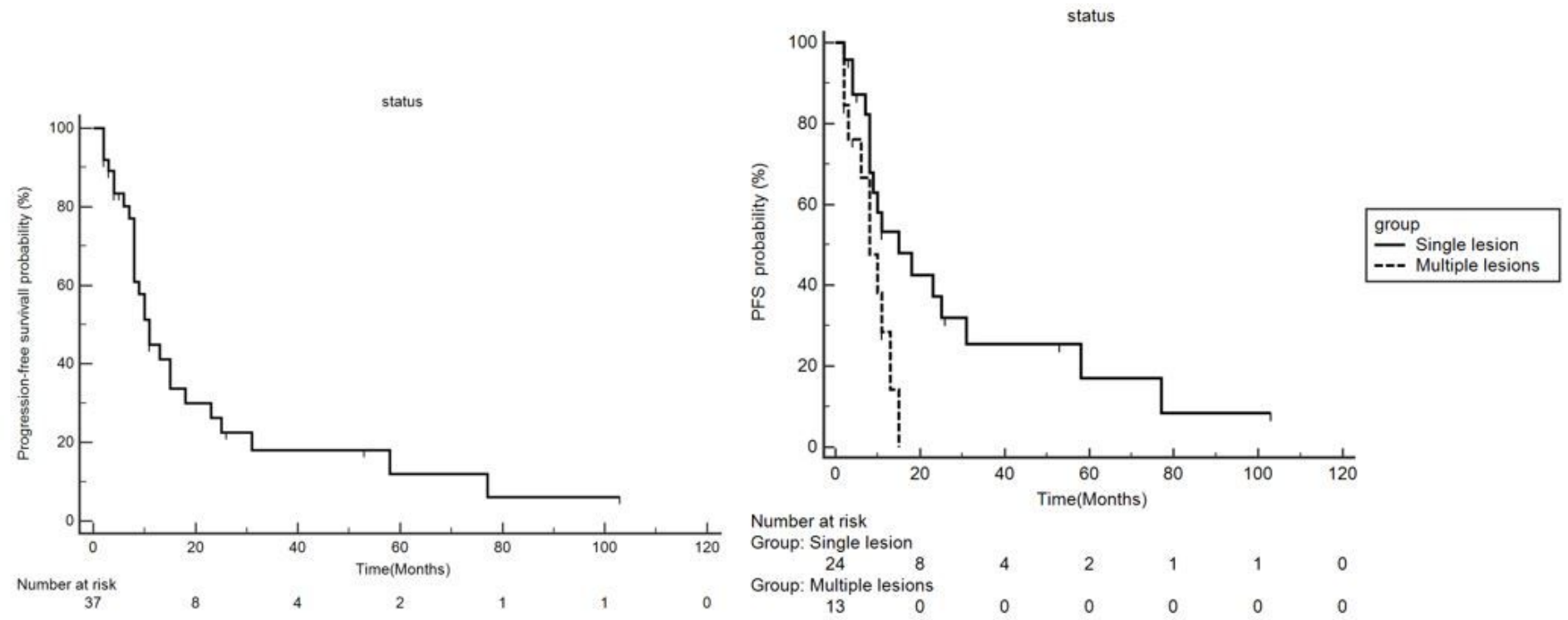

a

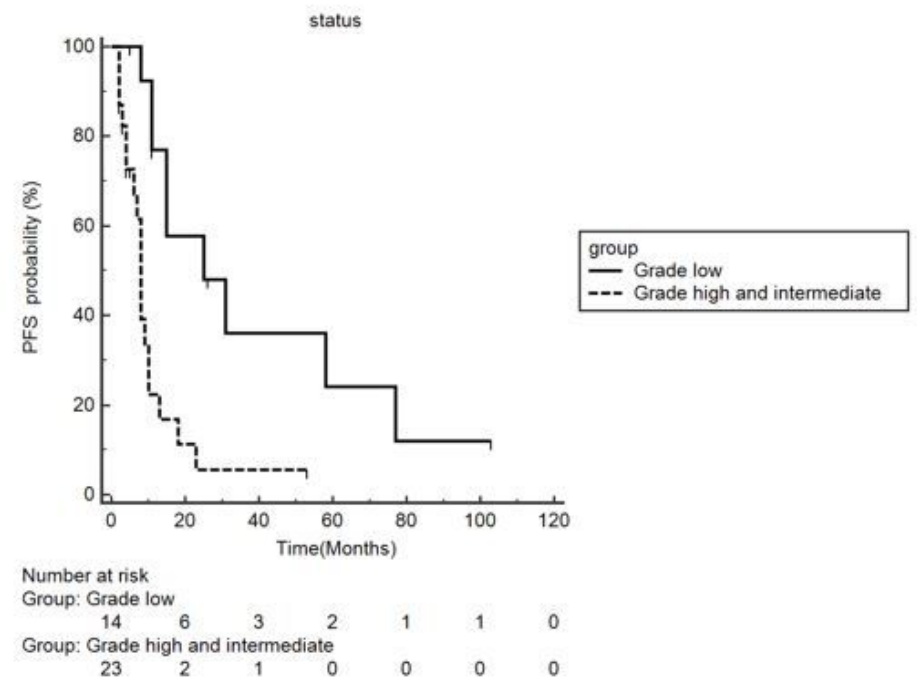

\section{Figure 3}

Kaplan-Meier plots for: a progression-free survival following stereotactic body radiation therapy (SBRT). b progression-free survival following stereotactic body radiation therapy (SBRT) stratified by single lesion (dashed line) and multiple alesions (solid line). c progression-free survival following stereotactic body radiation therapy (SBRT) stratified by low differentiation (dashed line) and high and intermediate (solid line). 

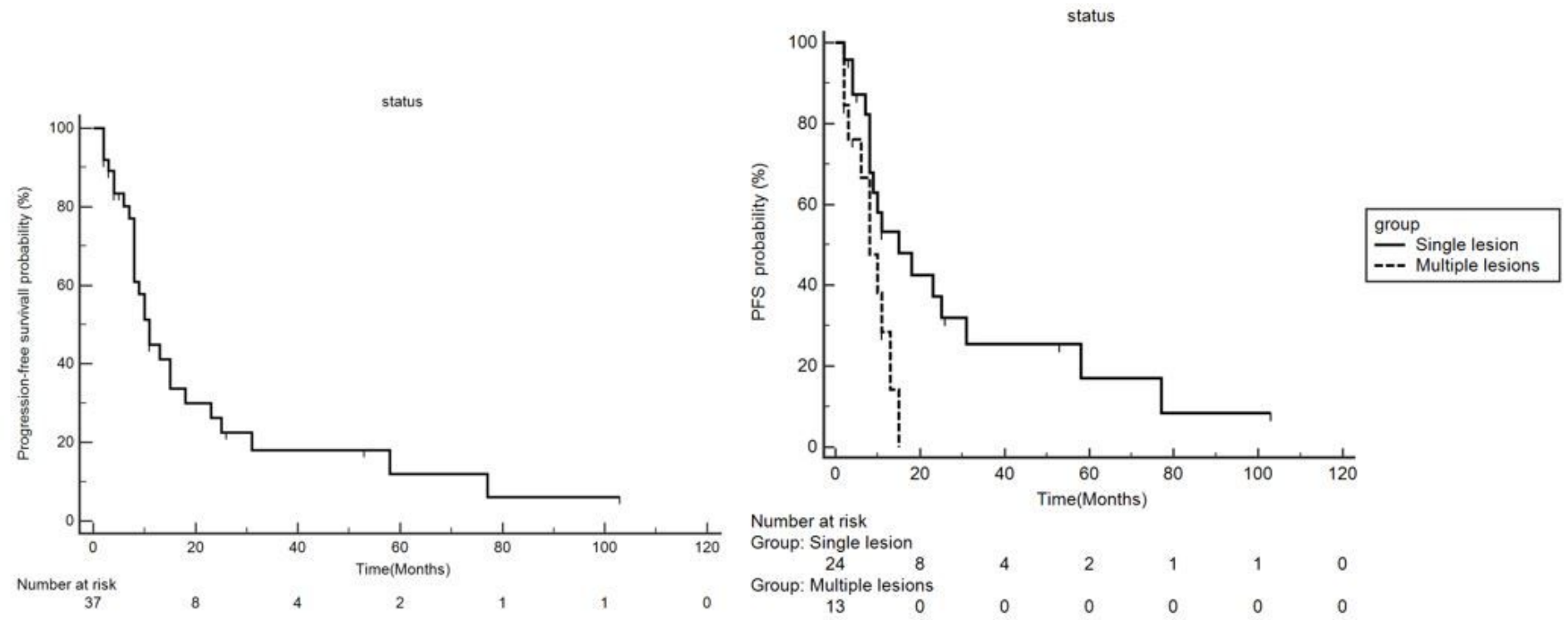

a

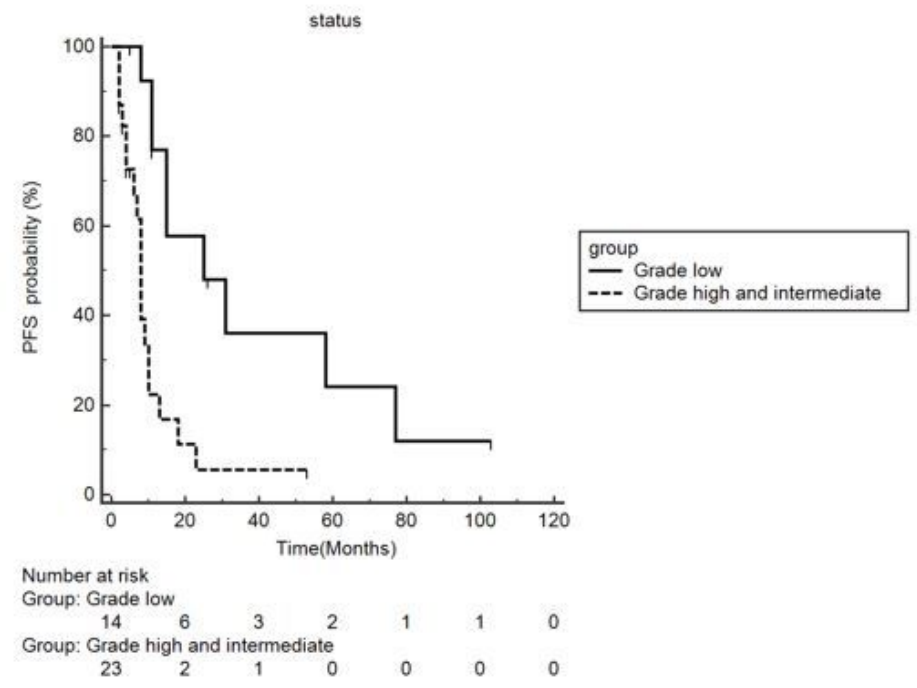

\section{Figure 3}

Kaplan-Meier plots for: a progression-free survival following stereotactic body radiation therapy (SBRT). b progression-free survival following stereotactic body radiation therapy (SBRT) stratified by single lesion (dashed line) and multiple alesions (solid line). c progression-free survival following stereotactic body radiation therapy (SBRT) stratified by low differentiation (dashed line) and high and intermediate (solid line). 


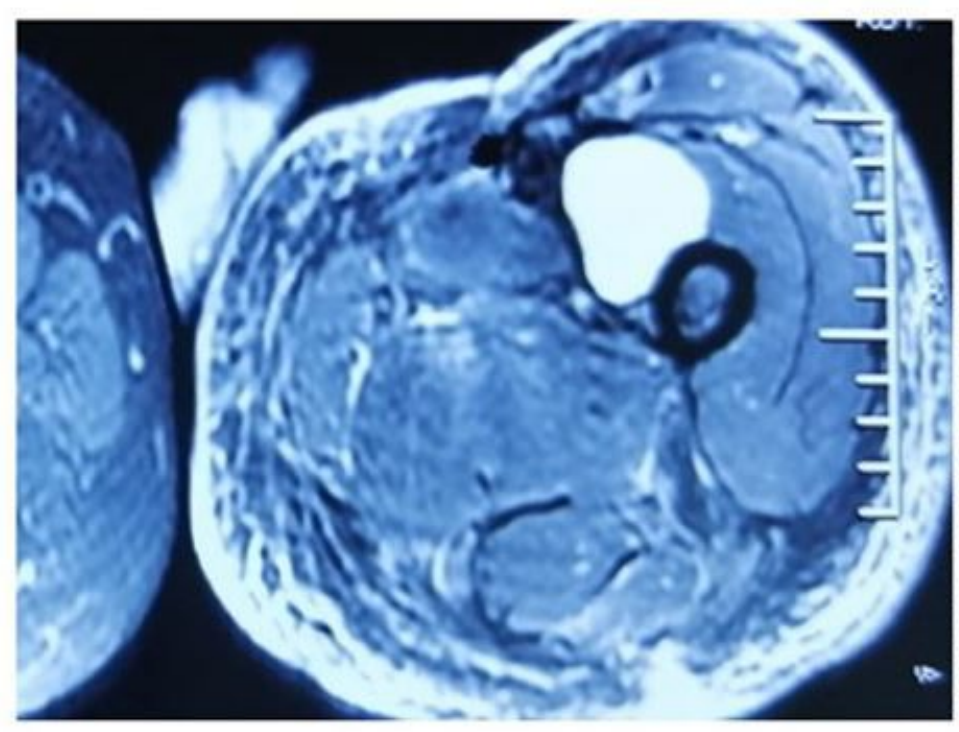

a

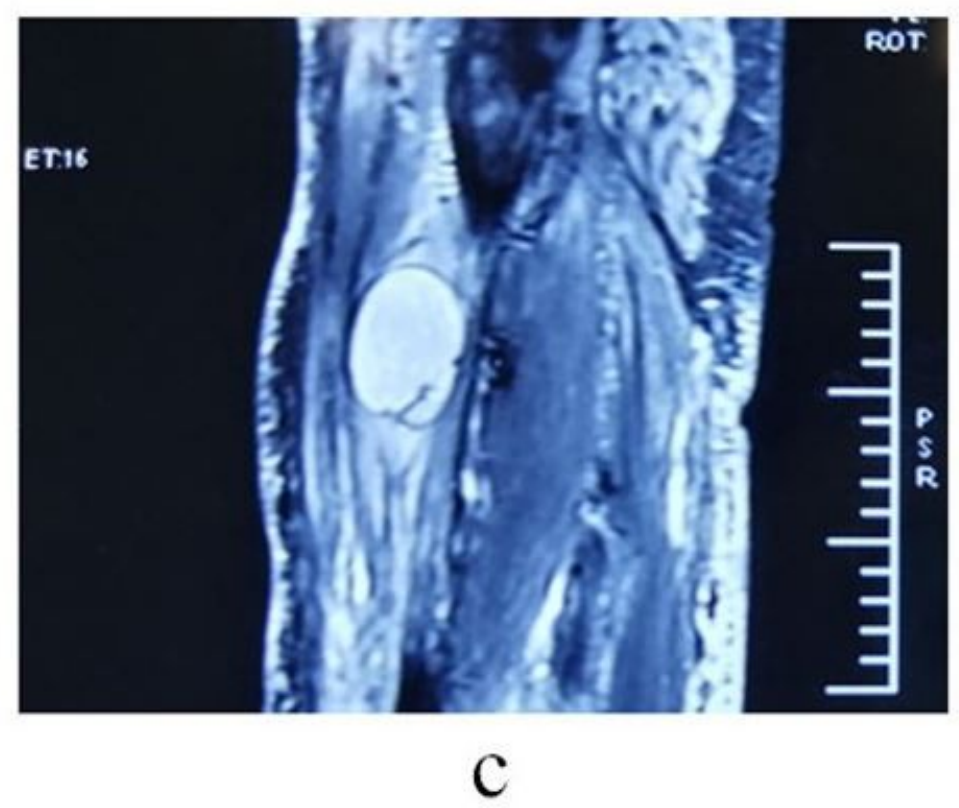

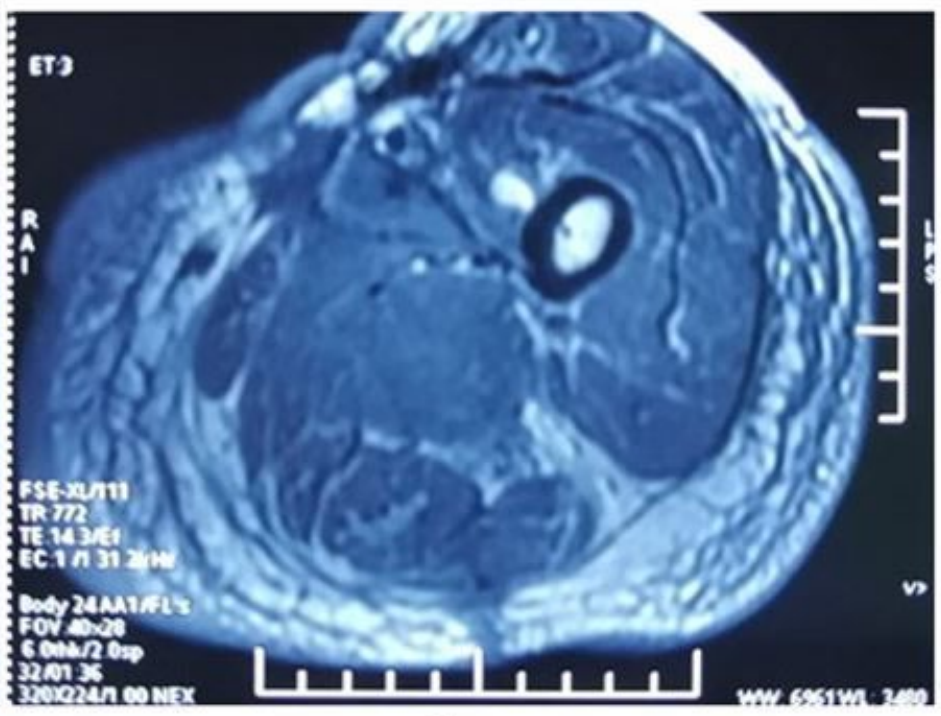

b
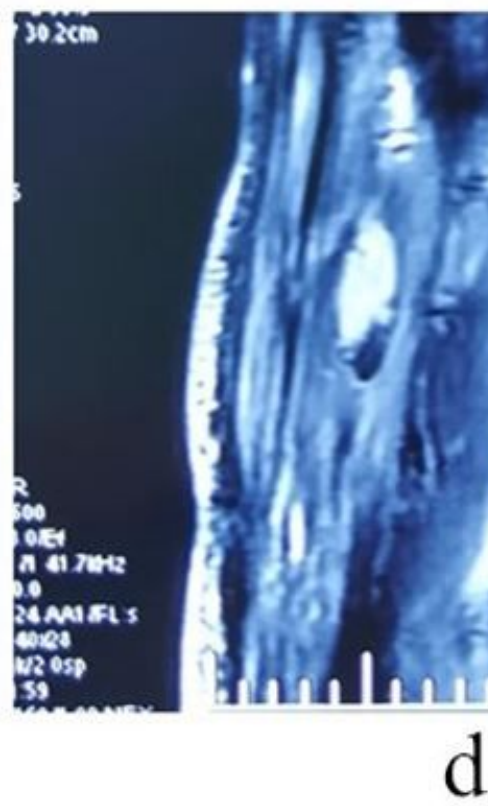

\section{Figure 4}

Recurrence of mucinous liposarcoma of the inner thighs in a 71-year-old male. Axial ( $a$ and c) and sagittal (b and d) T1-weighted images acquired with gadolinium before treatment ( $a$ and b) and after treatment (c and d). 


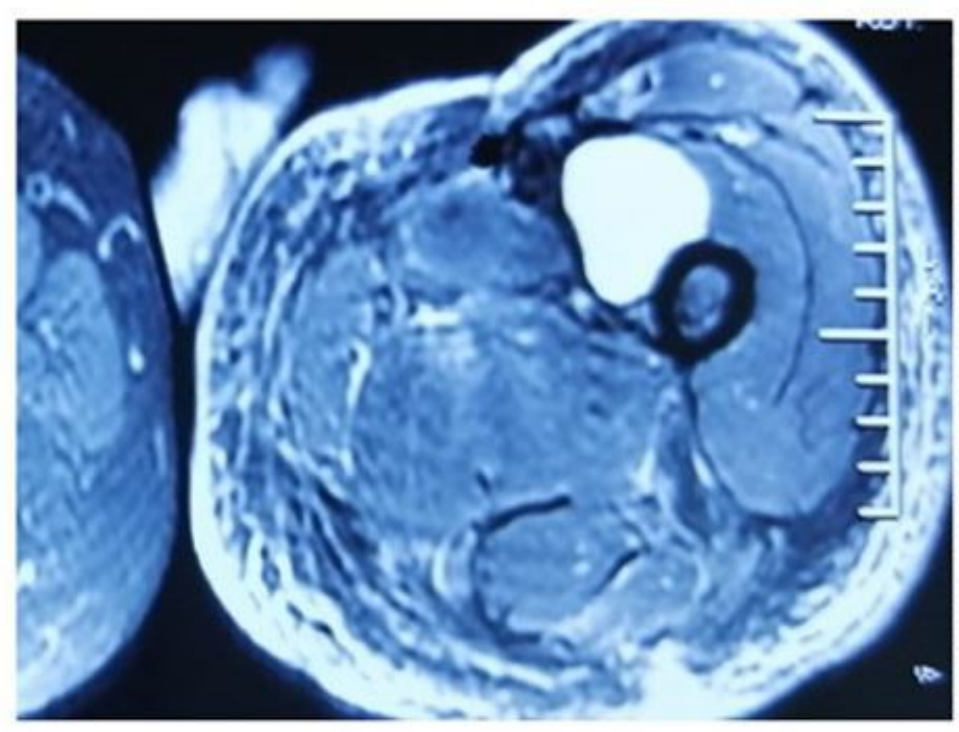

a

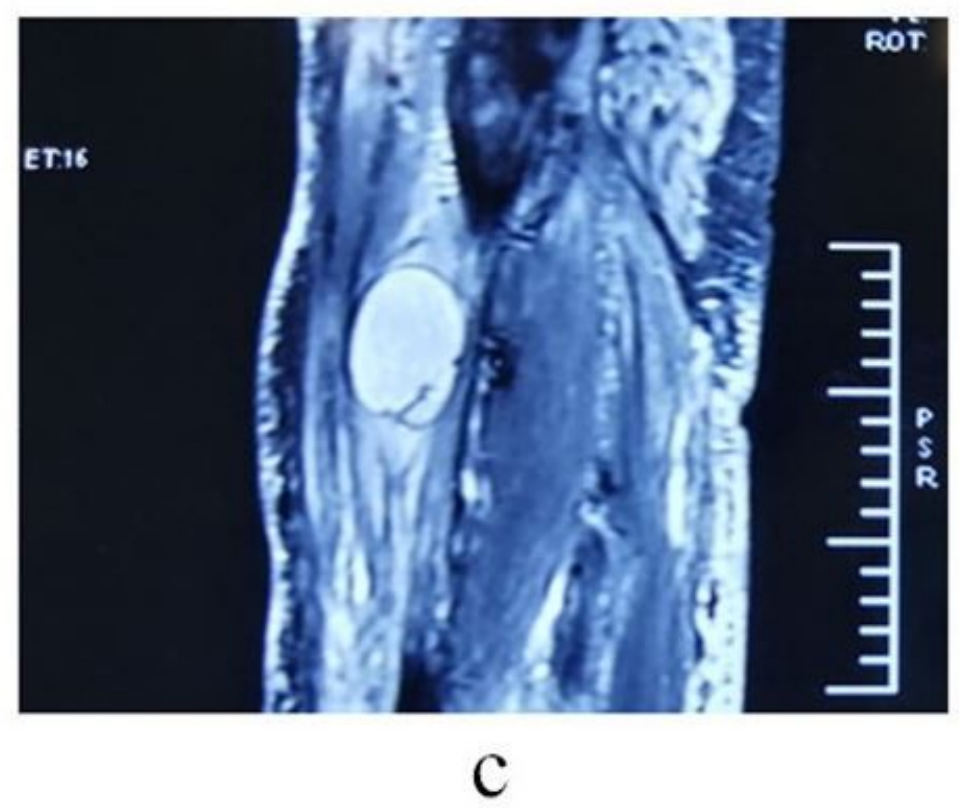

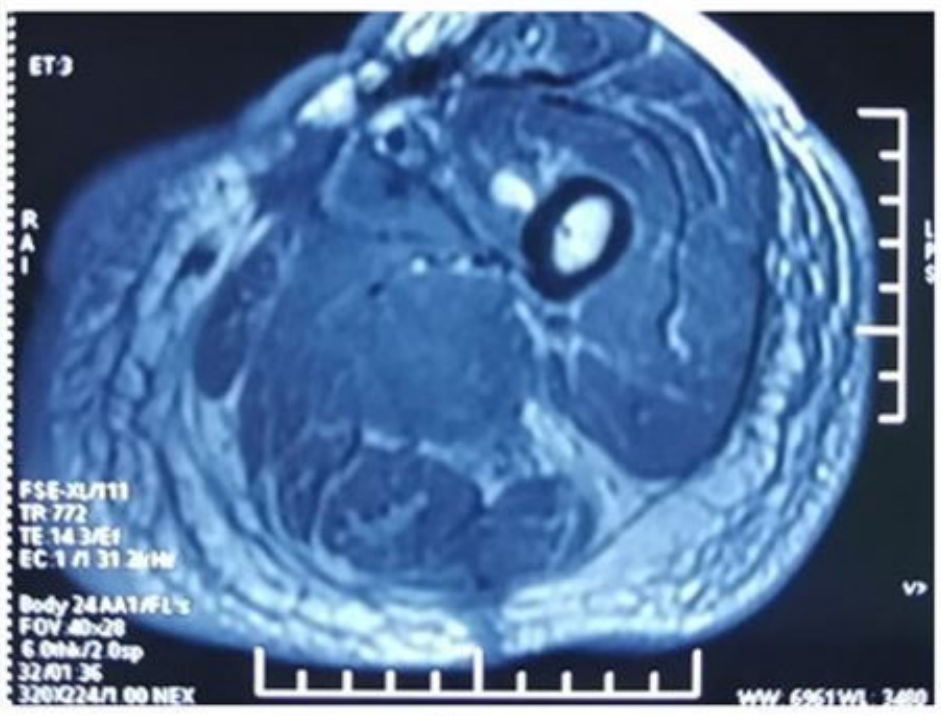

b
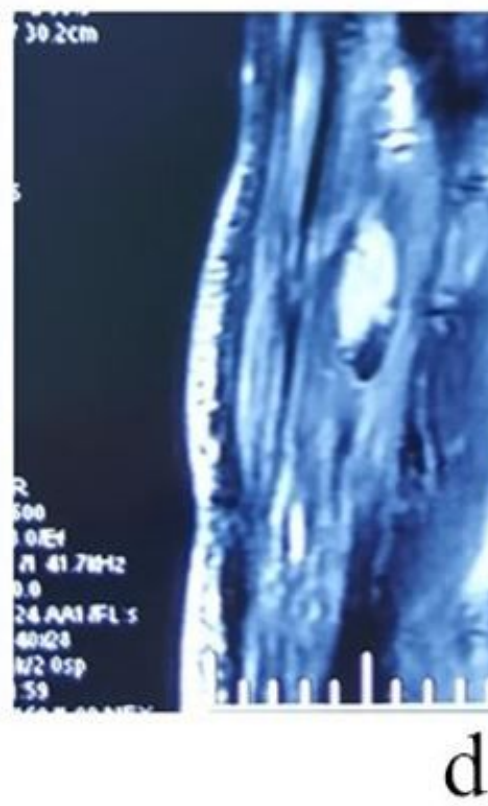

\section{Figure 4}

Recurrence of mucinous liposarcoma of the inner thighs in a 71-year-old male. Axial ( $a$ and c) and sagittal (b and d) T1-weighted images acquired with gadolinium before treatment ( $a$ and b) and after treatment (c and d). 